\title{
Technical challenges and limitations of current mouse models of ovarian cancer
}

\author{
Kenneth Garson ${ }^{1}$, Lisa F Gamwell ${ }^{1,2}$, Elizabeth MG Pitre ${ }^{1,2}$ and Barbara C Vanderhyden ${ }^{1,2^{*}}$
}

\begin{abstract}
The development of genetically engineered models (GEM) of epithelial ovarian cancer (EOC) has been very successful, with well validated models representing high grade and low grade serous adenocarcinomas and endometrioid carcinoma (EC). Most of these models were developed using technologies intended to target the ovarian surface epithelium (OSE), the cell type long believed to be the origin of EOC. More recent evidence has highlighted what is likely a more prevalent role of the secretory cell of the fallopian tube in the ontogeny of EOC, however none of the GEM of EOC have demonstrated successful targeting of this important cell type.

The precise technologies exploited to develop the existing GEM of EOC are varied and carry with them advantages and disadvantages. The use of tissue specific promoters to model disease has been very successful, but the lack of any truly specific OSE or oviductal secretory cell promoters makes the outcomes of these models quite unpredictable. Effecting genetic change by the administration of adenoviral vectors expressing Cre recombinase may alleviate the perceived need for tissue specific promoters, however the efficiencies of infection of different cell types is subject to numerous biological parameters that may lead to preferential targeting of certain cell populations.

One important future avenue of GEM of EOC is the evaluation of the role of genetic modifiers. We have found that genetic background can lead to contrasting phenotypes in one model of ovarian cancer, and data from other laboratories have also hinted that the exact genetic background of the model may influence the resulting phenotype. The different genetic backgrounds may modify the biology of the tumors in a manner that will be relevant to human disease, but they may also be modifying parameters which impact the response of the host to the technologies employed to develop the model.
\end{abstract}

Keywords: Ovarian cancer, Mouse models, Genetically engineered, Ovary, Oviduct, Ovarian surface epithelium

\section{Review}

Introduction

Recently a number of insightful reviews have summarized GEM of EOC [1-9]. This review will first briefly examine current hypotheses on the cell(s) of origin of human EOC, as this is the cornerstone for the development of GEM of EOC. Secondly, the numerous models of ovarian cancer will be briefly discussed in the context of the technological approaches exploited for model development. Importantly, the advantages, disadvantages and inherent assumptions implicit in these technologies will be discussed. Finally, we have found that the genetic

\footnotetext{
* Correspondence: bvanderhyden@ohri.ca

${ }^{1}$ Centre for Cancer Therapeutics, Ottawa Hospital Research Institute, Ottawa, ON K1H 8L6, Canada

${ }^{2}$ Department of Cellular and Molecular Medicine, Faculty of Medicine, University of Ottawa, Ottawa, ON K1H 8M5, Canada
}

background can impart dramatic changes in the phenotype of disease in a GEM of EOC and the latter part of this review will discuss the relevance of genetic background and inbred strains to future model development.

The fundamental premise in the design of GEM of EOC is the development of tools or strategies to target genetic change to the presumed precursors of the disease. Traditionally, the origin of human EOC was presumed to be in the OSE, or in the epithelial lining of inclusion cysts that had arisen from the OSE and the evidence supporting this has been extensively reviewed [10-14]. The OSE retains the potential to undergo Müllerian differentiation as evidenced by the expression of Müllerian markers in naturally forming inclusion cysts, in inclusion cysts arising at increased frequencies in mice harboring specific genetic lesions $[15,16]$ and in

\section{Biomed Central}


OSE coaxed into different Müllerian lineages following the introduction of specific Hoxa genes [17].

Recently, growing evidence has challenged this theory and identified the secretory cell of the distal fallopian tube as a putative EOC precursor [18-25]. While evidence favors a fallopian tube origin for a high proportion of high grade serous ovarian adenocarcinomas, there has not been sufficient evidence to rule out a parallel role for the OSE $[25,26]$.

Finally, it must be kept in mind that evidence of early precursors of EOC in the OSE or the secretory cell of the distal fallopian tube implicates not only these differentiated cell types as potential origins of the disease, but it also implicates putative progenitor or tissue stem cells as well [27-32].

\section{Targeting the mouse for models of ovarian cancer Direct expression of a transgene from a tissue specific promoter}

In the absence of a promoter candidate specific for OSE, Connolly et al. [33] found that the Amhr2 (also known as MISIIR) promoter was transcriptionally active in murine OSE in addition to reported expression in granulosa cells [34] and the stroma of the Müllerian duct [35]. In the first GEM of EOC, female mice expressing the SV40 early region (SV40TAg) from the Amhr2 promoter developed poorly differentiated serous tumors derived from the OSE. Interestingly, granulosa cell tumors did not arise in this model, despite the potential for the Amhr2 promoter to drive expression in granulosa cells
[34,35] and the potential for granulosa cells to become malignantly transformed by the SV40 early region $[36,37]$ or the SV40 large T antigen (TAg) [38].

In our laboratory, we noted in an independent Amhr2-SV40TAg transgenic line (Tg(Amhr2-SV40TAg) $1 \mathrm{Bcv}$ ) generated on the $\mathrm{FVB} / \mathrm{n}$ strain $^{\mathrm{a}}$, that in addition to evident TAg expression in the ovary, expression was also seen in the epithelium and stroma of the oviduct (Figure 1a) and in the epithelium of the uterus (Figure 1b). Expression of TAg in the uterine and oviductal epithelium was not expected from the endogenous Amhr2 promoter and may result from altered regulation of the ectopic promoter fragment. In order to examine potential tumorigenesis from the oviduct and uterus, ovaries were removed from mice 7-8 weeks of age. Tumors arising from the remaining reproductive tract were slower to develop and showed significantly more cells expressing PAX8 than tumors developing from the ovaries of the non-ovariectomized controls. Expression of PAX8, a marker of oviductal and uterine epithelium (Figure 1c, 1d, respectively), in tumors from ovariectomized mice may indicate their origin in the oviductal or uterine epithelium. Interestingly, several regions of papillary differentiation were found in tumors with PAX8 positivity (Figure 1e).

Direct targeting of SV40TAg expression to the oviductal secretory cells was attempted using the oviductspecific glycoprotein (Ovgp1) promoter [39]. Although oviductal tumors were reported they were not well characterized [39]. All mice developed uterine tumors and
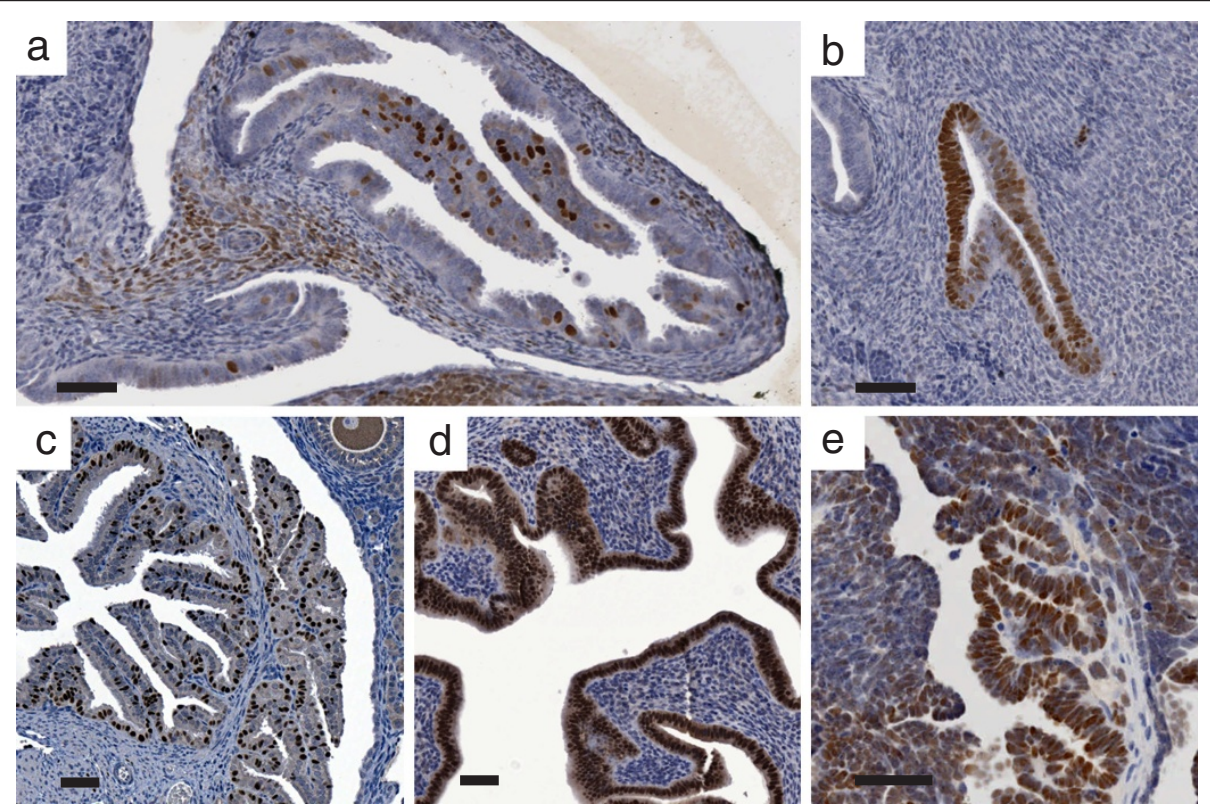

Figure 1 Expression of TAg and PAX8. TAg in the oviductal epithelium and stroma (a) and in the uterine epithelium (b) of FVB/n-Tg(Amhr2SV40TAg)1BCV mice as shown by immunohistochemistry. PAX8 expression in the normal oviduct (c), uterine epithelium (d) and papillary lesions of a tumor from an ovariectomized FVB/n-Tg(Amhr2-SV40TAg)1Bcv mouse (e). Scale bars represent $50 \mu \mathrm{M}$. 
$60 \%$ developed vaginal tumors, two other tissues with documented OVGP1 expression [40,41].

Other relevant models have induced premalignant changes, but not cancers, in the OSE and have implicated various signaling pathways in these changes. Expression of a constitutively active PIK3CA by the Amhr2 promoter led to OSE hyperplasia [42]; the expression of dnSMAD2 from the Amh promoter gave rise to ovarian inclusion cysts with Müllerian differentiation [43] and OSE in mice heterozygous for disabled-2 demonstrated surface dysplasia and papillomatosis [44].

While the direct transgene approach led to the first model of EOC, the implementation of such strategies remains unpredictable. Both the Amh and Amhr2 promoters express in both granulosa cells and OSE [33,43], yet their use to express the SV40TAg has led to granulosa cell tumors [38] and epithelial tumors [33], respectively. It is possible that there are subtle differences not only in the static expression from a promoter at a fixed time point, but also differences in the developmental timing of expression that might be critical for the phenotype of the model. It must not be forgotten that the expression of oncogenes in the earliest cell types that initiate promoter function may also alter the development of subsequent lineages of cells. This is in contrast to our notions of tumorigenesis, where dominant genetic changes occur stochastically in cells residing in organisms that for the most part have completed their developmental programs.

\section{Cre-lox conditional targeting: Tissue expression of Cre}

The first model exploiting the tissue-specific expression of Cre recombinase used the Fshr promoter to inactivate loxP-flanked (floxed) Brcal alleles in granulosa cells, however serous cystadenomas carrying unrecombined Brcal developed in the OSE [45]. Increased expression of aromatase [46], and alterations of the estrus cycle [47] due to the inactivation of Brcal may have collectively led to increased levels of estrogen [47] contributing to the observed changes in the OSE. While this model may seem unique, other examples in the female reproductive tract of genetic change in one compartment leading to hyperplasia or tumorigenesis in a second compartment have been reported recently $[48,49]$.

The Amhr2 promoter, used for the first GEM of EOC, has been exploited for the expression of $\mathrm{Cre}$ in a number of models. Expression of $\mathrm{Cre}$ from the endogenous Amhr2 promoter leads to conditional expression of $L a c Z$ in the Gtrosa26 ${ }^{t m 1 S o r}$ reporter mice as early as embryonic day 11.5 in female urogenital ridges, and in the female gonads and Müllerian ducts at embryonic day 12.5. In the adult mouse, expression of LacZ has been noted in the granulosa cells of follicles (not primary or primordial), thecal cells, corpus luteum, OSE and stromal cells of the oviduct and uterus [50]. Importantly, LacZ expression has not been reported in the oviductal or uterine epithelium.

The first low grade EOC model was reported by Fan et al. in 2009 [51]. Briefly, while examining the role of KRAS $^{\mathrm{G12D}}$ and PTEN signaling in granulosa cell development, they noted in triple transgenic mice (Ptenfl/fl; KrasG12D;Amhr2-Cre) that the loss of Pten and gain of $\operatorname{Kras}^{G 12 D}$ in the OSE led to the development of low grade serous adenocarcinomas. Activation of $\mathrm{Kras}^{\text {G12D }}$ alone by Amhr2-Cre did not lead to tumorigenesis, but rather growth arrest of granulosa cells and OSE hyperplasia [52]. Conditional loss of Pten alone in Amhr2-Cre mice resulted in alterations in granulosa [53,54] and uterine myometrial cells [55] but not OSE.

The OSE have also been targeted for alteration of the WNT pathway through the activation of $\beta$-catenin following the conditional deletion of exon $3\left(\mathrm{Ctnnb1}^{\Delta e x 3}\right)$ in Amhr2-Cre mice [56]. While all mice developed pretumoral nests of cells at the ovarian surface, $50 \%$ of mice progressed to develop EC. Combining the conditional activation of $C t n n b 1^{\Delta e x 3}$ with the conditional inactivation of Pten led to all mice developing EC. The phenotype of this model is in contrast with other reports that described the development of granulosa cell tumors in mice with conditional loss of Pten and conditional activation of $\beta$-catenin $\left(C t n n b 1^{\Delta e x 3}\right)$ induced either in the Amhr2-Cre line or through granulosa specific expression of Cre in the Cyp19Cre (Tg(CYP19A1-cre)1jri) line [57]. It is unclear from the reports $[53,56,57]$ whether the discrepancies relate to different interpretations of the pathological findings or whether possible differences in the breeding strategies to achieve the triple transgenic model animals led to different genetic backgrounds and outcomes.

The third transgenic model of EOC generated using the Amhr2-Cre transgenic strain was achieved through the conditional inactivation of Dicer and Pten, two genes frequently down-regulated in ovarian cancer [58]. While the phenotype of Amhr2-Cre mediated deletion of Pten is described above, the conditional deletion of Dicer alone resulted in smaller oviducts and uterine horns, a disorganized oviduct, changes in the glandular structure of the uterus [59] and alteration of ovarian follicle pools [60]. The combined conditional inactivation of both Dicer and Pten led to the development of high grade serous adenocarcinomas from the oviduct.

In contrast to evidence suggesting an origin for human ovarian cancer in the epithelium of the fallopian tube, Kim et al. identified early lesions in the stroma of the oviduct, consistent with the expression pattern from the Amhr2 promoter in this tissue [58]. These lesions and the resulting tumors expressed epithelial markers with gene expression patterns which aligned with human high 
grade serous ovarian carcinomas. The relationship of these early stromal lesions to the presumed fallopian tube secretory cell precursors of human disease is not clear. In the mouse, oviductal epithelial cells are not derived from stromal cells which express AMHR2 [61]. It would be of interest to determine if rare epithelial cells reside in the stroma of wild type mice or whether the loss of tumor suppressors in the oviductal mesenchyme leads to the ectopic development of epithelial precursors.

In summary, the targeting of genetic change through the inactivation of tumor suppressors (Brcal, Pten, Dicer) or the activation of oncogenes (Kras ${ }^{G 12 D}$, CtnnB1) using the tissue specific expression of $\mathrm{Cre}$ recombinase has led to EOC models encompassing benign tumors, $\mathrm{EC}$, low grade serous and high grade serous disease, however, there remain a number of caveats. First, the transient expression of $\mathrm{Cre}$ from a tissue specific promoter will mark that cell and all subsequent lineages with the designed genetic change, irrespective of whether the promoter driving $\mathrm{Cr}$ e has ceased to be transcriptionally active. This may exacerbate concerns about the loss of tumor suppressors or gain of oncogenes leading to models of "developmental cancer".

A second caveat of knock-in strains expressing Cre recombinase is dependent on the design. Transgenic lines such as the Amhr2-Cre line, which create a null allele [50], are used experimentally as heterozygotes. While no reports indicate any possible phenotypic consequences of haploinsufficiency of the Amhr2 gene, it remains a theoretical possibility that this may shape the phenotype of the resulting models. A phenotype based on haploinsufficiency was reported for Foxg1-cre mice [62] in which altered cell populations and tissue structure were observed in the brain of heterozygous mice. Further seemingly innocuous facets of the experiment can also lead to surprising phenotypic consequences. Mice carrying unrecombined floxed alleles can manifest phenotypes distinct from the wild type [63,64], and strains of mice expressing Cre from tissue specific promoters can present altered phenotypes in the absence of any floxed target genes [65].

\section{Cre-lox conditional targeting: Viral expression of Cre}

Adenoviral vectors expressing $\mathrm{Cre}$ recombinase ( $\mathrm{Ad}$ $C M V$-Cre) have been used for GEM of EOC to control both the time and location of Cre expression. Injection of virus through the bursal membrane or infundibulum has been used primarily to alter gene expression in the OSE, however this route also permits exposure of the bursal membrane and the oviductal epithelium to administered virus. The accessibility of the oviductal epithelium to introduced virus can clearly be seen in Figure 1c, which shows the externalized epithelium of the oviductal infundibulum, with secretory cells (PAX8 expressing) within $30 \mu \mathrm{M}$ of the OSE.

The first model of EOC using the intrabursal administration of $A d-C M V$-Cre reported high grade serous ovarian adenocarcinomas in mice that had conditional loss of Trp53 and $R b 1$ alleles following Cre-mediated recombination [66]. Interestingly, subtle variations in methodology may impact the phenotypes of this model, as different results have been noted in different laboratories. Clark-Knowles et al. found the loss of Trp53 and $R b 1$ alleles using intrabursal administration of $A d-C M V$ Cre led to the development of leiomyosarcomas, a phenotype that was also seen with $100 \%$ penetrance in mice with conditional deletion of Trp53 alleles alone [67]. In contrast, Flesken-Nikitin only observed the rare appearance of serous adenocarcinomas in $\operatorname{Trp} 53^{\text {loxP/loxP }}$ mice treated with $A d-C M V$-Cre [66]. A third report by Quinn et al. observed the rare occurrence of leiomyosarcomas in mice with conditional loss of Trp53. Possible differences in methodology, including different mouse genetic backgrounds, may have caused the variable outcome of these experiments. Novel in the experiments of Quinn et al. and Clark-Knowles et al. was a more aggressive or more penetrant disease when Brcal was deleted in addition to loss of $\operatorname{Trp} 53$ [67,68], a finding also noted for uterine leiomyosarcomas [69].

Clark-Knowles et al. (2009) speculated that one possible source of the leiomyosarcomas was from the smooth muscle cells of the bursal membrane. Recently, Szabova et al. [70] re-examined the role of Rb1, Trp53, Brca1 and Brca2 in EOC applying several new innovations that addressed two concerns. First, the concern that deletion of $R b 1$ alone may be ineffective due to functional compensation by $p 107$ or $p 130$ [71] led the authors to abrogate Rb1, p107 and p130 function through the Cre-dependent conditional expression of a deletion mutant of the SV40 Large $\mathrm{T}$ antigen, $\mathrm{T}_{121}$ [72]. $\mathrm{T}_{121}$ binds and inactivates $\mathrm{RB} 1$ and related proteins p107 and p130 [72,73] but does not inactivate TRP53. Furthermore, to eliminate the potential transformation of smooth muscle cells in the bursal membrane, conditional expression of $\mathrm{T}_{121}$ was from the cytokeratin 18 promoter. In contrast to the previous reports $[66,67]$, inactivation of RB1 (and p107, p130) following activation of the $T_{121}$ led to a range of abnormalities in the OSE including serous EOC (often high grade) in 18\% of mice. Single or double loss of Trp53, Brca1 or Brca2 function failed to generate OSE pathology while loss of $p 53$ alleles in conjunction with expression of $\mathrm{T}_{121}$ led to both the increased frequency and progression of high grade serous EOC [70].

In a related model, intrabursal administration of $A d-$ $C M V$-Cre was used to activate expression of the SV40 early region in mouse OSE [74]. The tumors emerging 
from this model were described as sex cord stromal tumors. While the SV40TAg is able to inactivate both RB1 (and p107, p130) and TRP53, additional roles in transformation have been described for both the large and small $t$ antigens [75] and how each of these contribute to the described phenotype is not known. Interestingly, treatment of mice with $17 \beta$-estradiol led to an earlier onset of tumors, decreased survival and distinctive papillary histology [74].

While targeting of OSE using the Amhr2-Cre transgenic to activate $\mathrm{Kras}^{\mathrm{GI2D}}$ and to inactivate Pten resulted in low grade serous adenocarcinomas [51], similar activation/ inactivation of these genes induced following the intrabursal injection of $\mathrm{Ad}-\mathrm{CMV}$-Cre led to the development of ovarian endometrioid adenocarcinomas [76]. While both of these reports indicate tumors arising from the OSE, the two different strategies may target different subsets of cells on the ovarian surface. Alternatively, the different outcomes in these two experiments may reflect the activation/deletion of these genes at different times in development. Inactivation of Pten alone following the intrabursal administration of $\mathrm{Ad}-\mathrm{CMV}$-Cre has been reported to lead to the development of endometrioid lesions [76] or serous papillary hyperplasia [77], again a variable outcome depending on the reporting laboratory.

Activation of $\mathrm{Kras}^{G 12 D}$ has also been evaluated in conjunction with the conditional loss of the Trp53 allele following intrabursal delivery of $\mathrm{Ad}-\mathrm{CMV}$-Cre [78]. While the resulting tumors were described as sarcomatoid ovarian carcinomas, the authors illustrated the utility of a more stochastic model of tumor initiation for understanding the evolution of immune cell infiltrates in the tumor microenvironment. Importantly, the authors reported that tumor growth is controlled initially by immune surveillance and the emergence of clinically significant tumors results from the development of an immunosuppressive tumor microenvironment.

Other investigators have addressed the loss of Pten in conjunction with further insult to the Akt pathway [79]. Interestingly, while one of the primary interests in the inactivation of Pten is to activate the Akt pathway, Kinross et al. inactivated Pten and activated a constitutively active mutant Pik3ca allele ( $\left.P i k 3 c a^{*}\right)$ expressed from the Pik3ca endogenous promoter. While the single lesions alone led to serous papillary hyperplasia, the combined loss of Pten and expression of Pik3ca* led to the development of high grade serous ovarian cancer.

Loss of PTEN function has also been coordinated with activation of the Wnt signaling pathway $[80,81]$. Wu et al. reported a statistical association of Pten mutations with Wnt pathway defects in ovarian endometrioid adenocarcinomas in clinical samples and used $A d-C M V$ Cre to activate the Wnt pathway by deletion of $A p c$ and the Akt pathway by deletion of Pten to give rise to ovarian endometrioid adenocarcinomas in $100 \%$ of mice. Interestingly, activation of the Akt and Wnt signaling pathways was also reported using Amhr2-Cre to inactivate Pten and activate the expression of a dominant stable $\beta$-catenin $[53,56]$, however depending on the reporting laboratory, the mice either developed EC [56] in agreement with $\mathrm{Wu}$ et al. or granulosa cell tumors [53].

In summary, the administration of $A d-C M V$-Cre intrabursally has led to models of both high grade serous and endometrioid adenocarcinomas. While Ad-CMV-Cre models require surgical intervention to initiate the tumorigenic process, the sudden induction of genetic mutation in the target cells in the adult is more relevant to the human disease than a developmentally regulated acquisition of genetic change. The exposure of the ovarian surface, bursal membrane, oviduct and in some instances granulosa cells [77] to intrabursally injected adenovirus represents a simple model of delivery of Cre, however the efficient infection of polarized epithelium of the oviduct and even polarized OSE [82] is much more complicated.

The successful targeting of a cell for expression of Cre recombinase from $\mathrm{Ad}-\mathrm{CMV}$-Cre vectors depends on the activity of the CMV promoter in that cell type and the level of expression of the virus receptor and coreceptors, CAR [83] and the $\alpha v \beta 3$ or $\alpha v \beta 5$ integrins [84], respectively. In polarized epithelium, infection can be restricted to the basolateral surface of the cell due to the absence of apically expressed CAR $[85,86]$. A number of factors can sensitize cells to apical infection, including the apical expression of alternate isoforms of CAR [87], and the expression of extrinsic factors such as CXCL8 [88] or lactoferrin [89]. Expression of both CXCL8 $[90,91]$ and lactoferrin $[92,93]$ has been reported in follicular fluid and within the fallopian tube. While successful infection of OSE is evident in the reported models, it cannot be assumed that all cells are equally sensitive to infection.

Previously, we have examined infection of the OSE following the intrabursal administration of varying titres of $A d-C M V-/ a c Z$. Although infection, measured by LacZ expression, was at times found throughout the entire ovarian surface, a subset of mice showed infection localized frequently at the apex of what appear to be corpora luteal structures (Figure 2). The reasons for such localized $L a c Z$ expression on the epithelial surface are not clear, but it could result from a number of mechanisms, including the selective expression of LacZ from the CMV promoter resident in the adenoviral vector or the selective infection of cells on the ovarian surface that had lost polarity during ovulatory wound repair. 

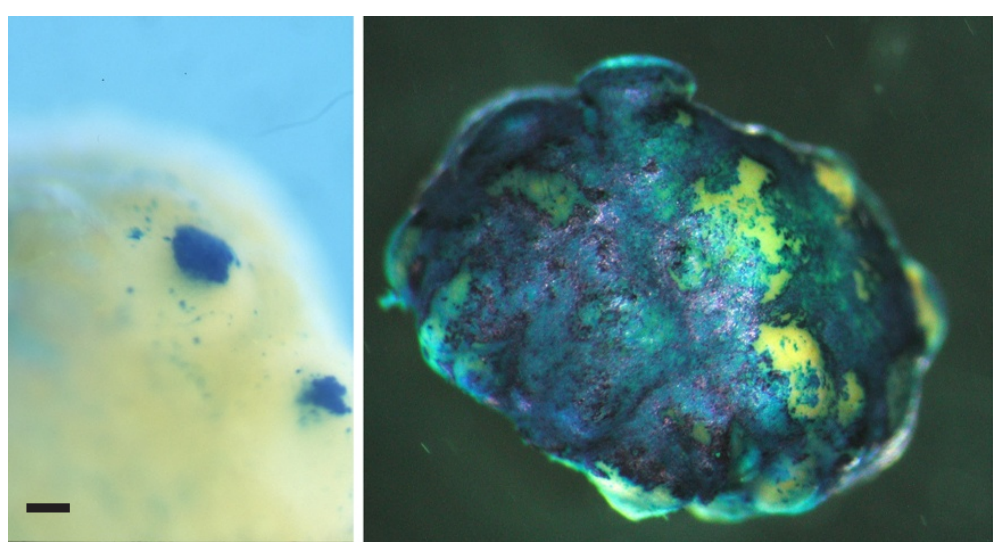

Figure 2 LacZ expression in Ad-CMV-lacZ treated ovaries. Intrabursal administration of $10^{7}$ (left panel) or $10^{8}$ (right panel) plaque forming units (pfu) of Ad-CMV-lacZ. Administration of $10^{7}$ pfu results in a selective infection of a subset of cells on the surface of the murine ovary (left). Ovaries were fixed and stained with X-gal to detect expression of $\beta$-galactosidase. The scale bar on the left panel indicates approximately $150 \mu \mathrm{M}$.

While empirical data from our laboratory and others have indicated that adenovirus can infect the epithelium of the ovary, oviduct and uterus [94], it remains a concern that subsets of cells may have varied sensitivities to infection which may influence the phenotype of the resulting models.

\section{Genetic background}

The importance of mouse strain on the investigation of transgenic models of cancer has been recently reviewed [95]. Our laboratory found striking phenotypic differences in a transgenic line, $\mathrm{Tg}(\mathrm{Amhr} 2-\mathrm{SV} 40 \mathrm{TAg}) 1 \mathrm{Bcv}$, depending on whether it was in a pure $\mathrm{FVB} / \mathrm{n}$ or a mixed

a
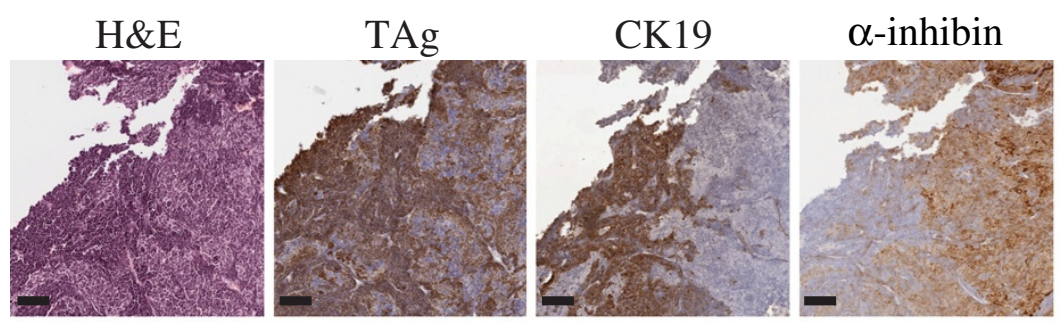

b

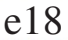

d1
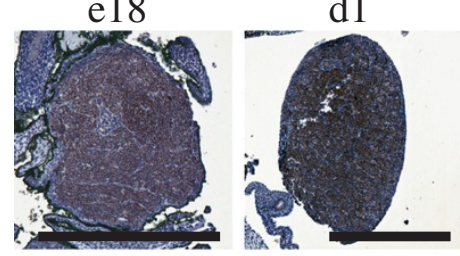

d5
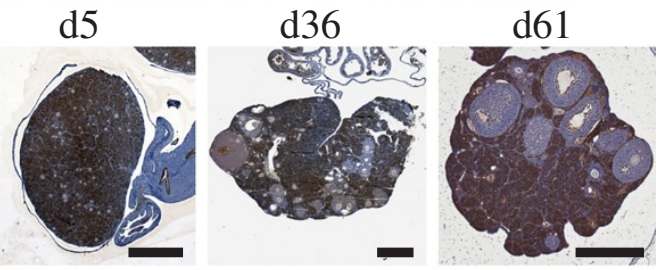

C

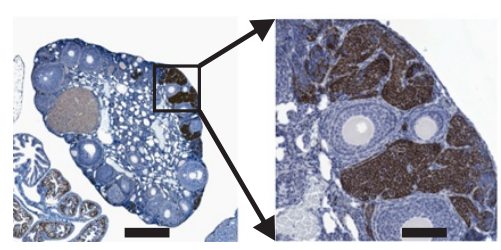

Figure 3 Effect of genetic strain on ovarian tumors in Tg(Amhr2-SV40TAg)1Bcv mice. Cytokeratin 19 (CK19) and a-inhibin expression in the FVB/n-Tg(Amhr2-SV40TAg)1Bcv (a) are localized to distinct regions of the tumor that appear mutually exclusive. TAg expression is found throughout the entire ovarian stroma as early as embryonic day 18 (b) with exclusion of expression from large follicles apparent at 36 and 61 days of age. Expression of TAg in the F1 ovaries from a cross of the FVB/n-Tg(Amhr2-SV40TAg)1Bcv to C57BI/6 mice is apparent after several weeks of age and then only localized to the ovarian cortex as shown (c, day 43). Scale bars indicate $100 \mu \mathrm{M}(\mathrm{a}), 500 \mu \mathrm{M}(\mathrm{b}+\mathrm{c})$ or $100 \mu \mathrm{M}(\mathrm{c}$, enlarged area). 
$\mathrm{FVB} / \mathrm{n} ; \mathrm{C} 57 \mathrm{Bl} / 6$ background (FVBB6F1). Ovarian tumors arising in $\mathrm{Tg}(\mathrm{Amhr} 2-\mathrm{SV} 40 \mathrm{TAg}) 1 \mathrm{Bcv}$ and independent $\mathrm{FVB} / \mathrm{n}$ transgenic founders showed regional expression of both cytokeratin and $\alpha$-inhibin that tended to be mutually exclusive (Figure $3 \mathrm{a}$ ). In the $\mathrm{FVB} / \mathrm{n}$ line, stromal hyperplasia of TAg expressing cells is evident as early as embryonic day 18 (Figure 3b). In contrast, F1 progeny of a backcross into the $\mathrm{C} 57 / \mathrm{Bl} 6$ strain revealed $\mathrm{TAg}$ expressing lesions only in the cortex of the ovary near the ovarian surface as late as 6 weeks of age (Figure 3c), a phenotype which is distinct from that observed in the pure $\mathrm{FVB} / \mathrm{n}$ background. Finally, the delayed initiation of ovarian cancer in the FVBB6F1 mice was reflected in a longer mean time to endpoint of 21 weeks compared to 15 weeks observed for the $\mathrm{Tg}(\mathrm{Amhr} 2-\mathrm{SV} 40 \mathrm{TAg}) 1 \mathrm{Bcv}$ in the pure $\mathrm{FVB} / \mathrm{n}$ background.

A number of the EOC models described in this review have targeted similar pathways with different consequences. The modeling of Trp53 and $R b 1$ loss following the intrabursal delivery of $\mathrm{Ad}-\mathrm{CMV}$-Cre was performed by two laboratories with different outcomes $[66,67]$. The penetrance and phenotype of tumors arising in $A d$ $C M V$-Cre treated animals with only loss of Trp53 was also varied between reports [66-68]. While these groups initially used the same strains of mice, Flesken-Nikitin et al. reported the backcross of their strains to the $\mathrm{FVB} / \mathrm{n}$ background. Although not verified, the varied phenotypes in these studies may be a consequence of different genetic backgrounds.

One future goal for the continued development of GEM of EOC is to identify modifiers of the disease through crosses with genetically varied strains of mice. While libraries of recombinant inbred strains have been developed for this purpose [96], the requirement of many of the EOC models for three transgenes and a requirement for homozygosity of floxed tumor suppressor alleles makes the breeding for such a systematic approach challenging. In addition, the use of GEM of EOC to screen for genetic modifiers of disease that are relevant to human will require sorting through "noise" which is related to genetic modifiers of "technology" as opposed to modifiers of the disease. For example, strain differences may modulate parameters that influence the efficiency of viral infection, or subtly modify temporal patterns of promoter function.

\section{Conclusions}

This review has examined some of the technological parameters that have shaped the existing GEM of EOC. The modeling of EOC has been very successful, with

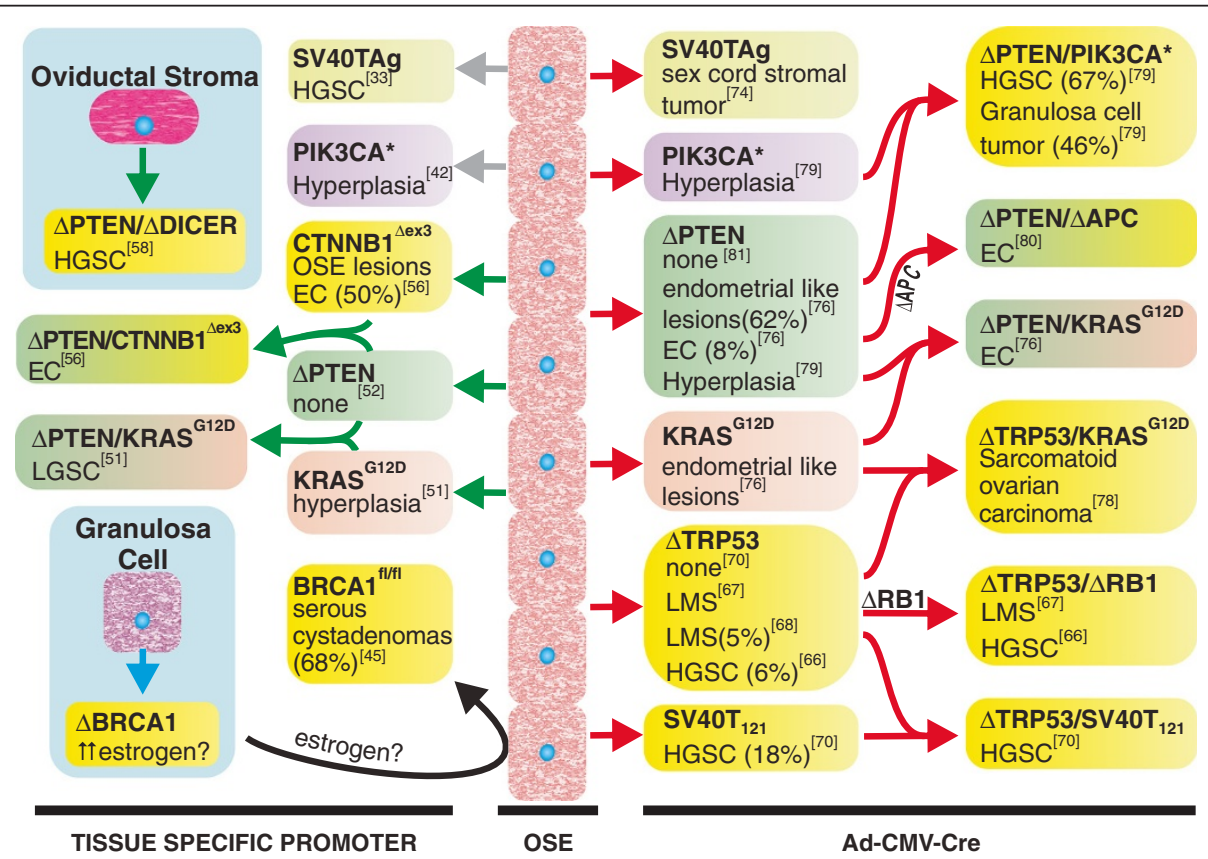

Figure 4 GEM of EOC. Outline of current models of EOC originating from genetic modification of OSE (centre), granulosa cells (bottom left) and oviductal stroma (top left). Phenotypes of OSE carrying single genetic lesions induced by Ad-CMV-Cre (red arrows) or tissue specific expression of oncogenes using the Amhr2 promoter (gray arrows), or expression of Cre from the FSHR promoter (blue arrow) or expression of Cre from the endogenous Amhr2 promoter (green arrows) are indicated. Murine models elicited phenotypes consistent with high grade serous ovarian cancer (HGSC), low grade serous ovarian cancer (LGSC), endometrioid ovarian cancer (EC), leiomyosarcomas (LMS), or the indicated phenotypes. Penetrance of the noted phenotypes, when less than $80 \%$, is expressed as the percentage of animals affected and displayed in brackets. Phenotypes of models are presented in yellow backgrounds, however models based on the activation/inactivation of similar pathways by separate means (eg. Ad-CMV-Cre versus Amhr2-Cre) are shaded with the same colors to facilitate comparison. 
well validated models representing high grade serous adenocarcinoma $[33,58,66,70,79]$, low grade serous adenocarcinoma [51], and endometrioid carcinoma $[56,76,80]$ (Figure 4). Eight GEM of EOC derived from OSE adds weight to the notion that the OSE retains a plasticity that does not preclude malignant transformation into cancers with evident Müllerian differentiation. The lack of GEM of EOC representing cancers arising primarily from the oviductal epithelium may be a consequence of inefficient targeting strategies.

Overall, the development of GEM of human cancers is a balance between convenience and authenticity. By some measures, the ultimate GEM of EOC would be a transgenic model requiring no intervention yet yielding $100 \%$ penetrance in mature animals of a phenocopy of the human disease with a predictable onset and highly consistent endpoint. While useful for statistical analysis of survival in therapeutic trials, this type of model is in stark contrast to the human disease which arises stochastically, in varied genetic backgrounds with highly variable rates of progression.

Now that some excellent models of EOC have been derived, it is time to develop models that may be less predictable, yet designed with imaging in mind such that $100 \%$ penetrance and highly defined endpoints are not essential. Consistent with the development of more stochastic models of ovarian cancer, GEM which exhibit genomic instability [68,97], a prominent feature of high grade serous EOC, should be important for future model development. Importantly, rather than modelling the developmental emergence of tumors through the expression of oncogenes or deletion of functional tumor suppressors using developmentally regulated promoters, inducible systems targeting the oviductal epithelium and OSE are needed such that genetic changes can be introduced more stochastically without the requirement for surgical intervention. The initiation of tumorigenesis in the adult mouse would not only better reflect the origin of ovarian cancer in women, but it also offers a more relevant examination of the interplay of the immune system with emerging tumors [78]. In addition, controlled timing of tumorigenesis in the adult mouse would allow some flexibility in studying the disease as a function of age, including manipulation of the hormonal status of the mice either through hormonal supplementation [74] or induction of menopause [98]. This would provide an enhanced relevance of GEM of EOC, but the challenges remain on how to effectively target the appropriate cells using available technologies.

\section{Endnotes}

${ }^{a}$ All animal experiments described in this study were performed according to the Guide to the Care and Use of Experimental Animals established by the Canadian Council on Animal Care.

\section{Abbreviations}

Amh: Anti-Müllerian hormone; Amhr2: Anti-Müllerian hormone type 2 receptor; EC: Endometrioid carcinoma; Fshr: Follicle stimulating hormone receptor; HGSC: High grade serous carcinoma; LacZ: ß-galactosidase; LGSC: Low grade serous carcinoma; LMS: leiomyosarcoma; MISIIR: Müllerian inhibiting substance type 2 receptor; Ovgp1: oviduct specific glycoprotein: OSE: Ovarian surface epithelium; SV40TAg: SV40 early region; TAg: SV40 large $T$ antigen

\section{Competing interests}

The authors declare that they have no competing interests.

\section{Authors' contributions}

KG, LFG and EMGP carried out the characterization of the Tg(Amhr2SV40TAg)1Bcv transgenic line. KG participated in the design of the studies and the draft of the manuscript. BCV conceived of the study and participated in the preparation of the manuscript. All authors read and approved the final manuscript.

\section{Acknowledgments}

The authors wish to thank Elizabeth Macdonald and Kerri Courville for their assistance with the generation of the animal models whose characterization is described herein. We are grateful to Dr. Douglas Gray for his critical review of this manuscript. The Amhr2-TAg transgene was kindly provided by Drs. Denise Connolly and Thomas Hamilton (Fox Chase Cancer Center, PA). This work was supported by grants to BCV from the Canadian Institutes of Health Research and the Ontario Institute for Cancer Research.

Received: 16 October 2012 Accepted: 22 November 2012

Published: 29 November 2012

\section{References}

1. Connolly DC, Hensley HH: Xenograft and Transgenic Mouse Models of Epithelial Ovarian Cancer and Non Invasive Imaging Modalities to Monitor Ovarian Tumor Growth In situ -Applications in Evaluating Novel Therapeutic Agents. Curr Protoc Pharmacol 2009, 45:14 12 11-14 1226.

2. Fong MY, Kakar SS: Ovarian cancer mouse models: a summary of current models and their limitations. J Ovarian Res 2009, 2:12.

3. Lu KH, Yates MS, Mok SC: The monkey, the hen, and the mouse: models to advance ovarian cancer chemoprevention. Cancer Prev Res (Phila) 2009, 2:773-775

4. Sale S: Genetically engineered mouse models of ovarian cancer and their utility in drug discovery. Curr Protoc Pharmacol 2009, Chapter 14(Unit 14):11

5. King SM, Burdette JE: Evaluating the progenitor cells of ovarian cancer: analysis of current animal models. BMB Rep 2011, 44:435-445.

6. Mullany LK, Richards JS: Minireview: animal models and mechanisms of ovarian cancer development. Endocrinology 2012, 153:1585-1592.

7. Shan W, Liu J: Epithelial ovarian cancer: focus on genetics and animal models. Cell Cycle 2009, 8:731-735.

8. Garson K, Shaw TJ, Clark KV, Yao DS, Vanderhyden BC: Models of ovarian cancer-are we there yet? Mol Cell Endocrinol 2005, 239:15-26.

9. Cheon DJ, Orsulic S: Mouse models of cancer. Annu Rev Pathol 2011, 6:95-119.

10. Bell DA: Origins and molecular pathology of ovarian cancer. Mod Pathol 2005, 18(Suppl 2):S19-32.

11. Bell DA, Scully RE: Early de novo ovarian carcinoma. A study of fourteen cases. Cancer 1994, 73:1859-1864.

12. Pothuri $B$, Leitao MM, Levine DA, Viale A, Olshen AB, Arroyo C, Bogomolniy F, Olvera N, Lin O, Soslow RA, et al: Genetic analysis of the early natural history of epithelial ovarian carcinoma. PLOS One 2010, 5:e10358.

13. Auersperg N, Woo MM, Gilks CB: The origin of ovarian carcinomas: a developmental view. Gynecol Oncol 2008, 110:452-454

14. Feeley KM, Wells M: Precursor lesions of ovarian epithelial malignancy. Histopathology 2001, 38:87-95.

15. Gendronneau G, Boucherat O, Aubin J, Lemieux M, Jeannotte L: The loss of Hoxa5 function causes estrous acyclicity and ovarian epithelial inclusion cysts. Endocrinology 2012, 153:1484-1497. 
16. Burdette JE, Oliver RM, Ulyanov V, Kilen SM, Mayo KE, Woodruff TK: Ovarian epithelial inclusion cysts in chronically superovulated CD1 and Smad2 dominant-negative mice. Endocrinology 2007, 148:3595-3604

17. Cheng W, Liu J, Yoshida H, Rosen D, Naora H: Lineage infidelity of epithelial ovarian cancers is controlled by HOX genes that specify regional identity in the reproductive tract. Nat Med 2005, 11:531-537.

18. Dubeau L: The cell of origin of ovarian epithelial tumors and the ovarian surface epithelium dogma: does the emperor have no clothes? Gynecol Oncol 1999, 72:437-442.

19. Piek JM, van Diest PJ, Zweemer RP, Jansen JW, Poort-Keesom RJ, Menko FH, Gille JJ, Jongsma AP, Pals G, Kenemans P, Verheijen RH: Dysplastic changes in prophylactically removed Fallopian tubes of women predisposed to developing ovarian cancer. J Pathol 2001, 195:451-456.

20. Carcangiu ML, Radice P, Manoukian S, Spatti G, Gobbo M, Pensotti V Crucianelli R, Pasini B: Atypical epithelial proliferation in fallopian tubes in prophylactic salpingo-oophorectomy specimens from BRCA1 and BRCA2 germline mutation carriers. Int J Gynecol Pathol 2004, 23:35-40.

21. Lee Y, Miron A, Drapkin R, Nucci MR, Medeiros F, Saleemuddin A, Garber J, Birch C, Mou H, Gordon RW, et al: A candidate precursor to serous carcinoma that originates in the distal fallopian tube. J Pathol 2007 211:26-35.

22. Carlson JW, Miron A, Jarboe EA, Parast MM, Hirsch MS, Lee Y, Muto MG, Kindelberger D, Crum CP: Serous tubal intraepithelial carcinoma: its potential role in primary peritoneal serous carcinoma and serous cancer prevention. J Clin Oncol 2008, 26:4160-4165.

23. Folkins AK, Jarboe EA, Saleemuddin A, Lee Y, Callahan MJ, Drapkin R, Garber JE, Muto MG, Tworoger S, Crum CP: A candidate precursor to pelvic serous cancer ( $p 53$ signature) and its prevalence in ovaries and fallopian tubes from women with BRCA mutations. Gynecol Oncol 2008, 109:168-173.

24. Jarboe E, Folkins A, Nucci MR, Kindelberger D, Drapkin R, Miron A, Lee $Y$, Crum CP: Serous carcinogenesis in the fallopian tube: a descriptive classification. Int J Gynecol Pathol 2008, 27:1-9.

25. Crum CP, Mckeon FD, Xian W: BRCA, the oviduct, and the space and time continuum of pelvic serous carcinogenesis. Int J Gynecol Cancer 2012, 22(Suppl 1):S29-34.

26. Roh MH, Kindelberger D, Crum CP: Serous tubal intraepithelial carcinoma and the dominant ovarian mass: clues to serous tumor origin? Am J Surg Pathol 2009, 33:376-383

27. Paik DY, Janzen DM, Schafenacker AM, Velasco VS, Shung MS, Cheng D, Huang J, Witte ON, Memarzadeh S: Stem-like epithelial cells are concentrated in the distal end of the fallopian tube: a site for injury and serous cancer initiation. Stem Cells 2012, 30:2487-2497.

28. Gamwell LF, Collins O, Vanderhyden BC: The Mouse Ovarian Surface Epithelium Contains a Population of LY6A (SCA-1) Expressing Progenitor Cells That Are Regulated by Ovulation-Associated Factors. Biol Reprod 2012, 87:80.

29. Virant-Klun I, Skutella T, Stimpfel M, Sinkovec J: Ovarian surface epithelium in patients with severe ovarian infertility: a potential source of cells expressing markers of pluripotent/multipotent stem cells. J Biomed Biotechnol 2011, 2011:381928.

30. Chang HL, MacLaughlin DT, Donahoe PK: Somatic stem cells of the ovary and their relationship to human ovarian cancers. Cambridge (MA): StemBook; 2008.

31. Szotek PP, Chang HL, Brennand K, Fujino A, Pieretti-Vanmarcke R, Lo Celso C, Dombkowski D, Preffer F, Cohen KS, Teixeira J, Donahoe PK: Normal ovarian surface epithelial label-retaining cells exhibit stem/progenitor cell characteristics. Proc Natl Acad Sci U S A 2008, 105:12469-12473.

32. Motohara T, Masuko S, Ishimoto T, Yae T, Onishi N, Muraguchi T, Hirao A, Matsuzaki $Y$, Tashiro $\mathrm{H}$, Katabuchi $\mathrm{H}$, et al: Transient depletion of p53 followed by transduction of c-Myc and K-Ras converts ovarian stem-like cells into tumor-initiating cells. Carcinogenesis 2011, 32:1597-1606.

33. Connolly DC, Bao R, Nikitin AY, Stephens KC, Poole TW, Hua X, Harris SS, Vanderhyden $\mathrm{BC}$, Hamilton TC: Female mice chimeric for expression of the simian virus $40 \mathrm{TAg}$ under control of the MISIIR promoter develop epithelial ovarian cancer. Cancer Res 2003, 63:1389-1397.

34. Baarends WM, Uilenbroek JT, Kramer P, Hoogerbrugge JW, van Leeuwen EC, Themmen AP, Grootegoed JA: Anti-mullerian hormone and anti-mullerian hormone type II receptor messenger ribonucleic acid expression in rat ovaries during postnatal development, the estrous cycle, and gonadotropin-induced follicle growth. Endocrinology 1995, 136:4951-4962.
35. Arango NA, Kobayashi A, Wang $Y$, Jamin SP, Lee HH, Orvis GD, Behringer RR: A mesenchymal perspective of Mullerian duct differentiation and regression in Amhr2-lacZ mice. Mol Reprod Dev 2008, 75:1154-1162.

36. Kananen K, Markkula M, Rainio E, Su JG, Hsueh AJ, Huhtaniemi IT: Gonadal tumorigenesis in transgenic mice bearing the mouse inhibin alphasubunit promoter/simian virus T-antigen fusion gene: characterization of ovarian tumors and establishment of gonadotropin-responsive granulosa cell lines. Mol Endocrinol 1995, 9:616-627.

37. Garson K, Macdonald E, Dube M, Bao R, Hamilton TC, Vanderhyden BC: Generation of tumors in transgenic mice expressing the SV40 T antigen under the control of ovarian-specific promoter 1. J Soc Gynecol Investig 2003, 10:244-250

38. Dutertre M, Gouedard L, Xavier F, Long WQ, di Clemente N, Picard JY, Rey R: Ovarian granulosa cell tumors express a functional membrane receptor for anti-Mullerian hormone in transgenic mice. Endocrinology 2001, 142:4040-4046.

39. Miyoshi I, Takahashi K, Kon Y, Okamura T, Mototani Y, Araki Y, Kasai N: Mouse transgenic for murine oviduct-specific glycoprotein promoterdriven simian virus 40 large T-antigen: tumor formation and its hormonal regulation. Mol Reprod Dev 2002, 63:168-176.

40. Woo MM, Gilks CB, Verhage HG, Longacre TA, Leung PC, Auersperg N: Oviductal glycoprotein, a new differentiation-based indicator present in early ovarian epithelial neoplasia and cortical inclusion cysts. Gynecol Oncol 2004, 93:315-319.

41. Woo MM, Alkushi A, Verhage HG, Magliocco AM, Leung PC, Gilks CB, Auersperg N: Gain of OGP, an estrogen-regulated oviduct-specific glycoprotein, is associated with the development of endometrial hyperplasia and endometrial cancer. Clin Cancer Res 2004, 10:7958-7964

42. Liang S, Yang N, Pan Y, Deng S, Lin X, Yang X, Katsaros D, Roby KF, Hamilton TC, Connolly DC, et al: Expression of activated PIK3CA in ovarian surface epithelium results in hyperplasia but not tumor formation. PLoS One 2009, 4:e4295.

43. Bristol-Gould SK, Hutten CG, Sturgis C, Kilen SM, Mayo KE, Woodruff TK: The development of a mouse model of ovarian endosalpingiosis. Endocrinology 2005, 146:5228-5236.

44. Yang DH, Fazili Z, Smith ER, Cai KQ, Klein-Szanto A, Cohen C, Horowitz IR Xu XX: Disabled-2 heterozygous mice are predisposed to endometrial and ovarian tumorigenesis and exhibit sex-biased embryonic lethality in a p53-null background. Am J Pathol 2006, 169:258-267.

45. Chodankar R, Kwang S, Sangiorgi F, Hong H, Yen HY, Deng C, Pike MC, Shuler CF, Maxson R, Dubeau L: Cell-nonautonomous induction of ovarian and uterine serous cystadenomas in mice lacking a functional Brca1 in ovarian granulosa cells. Curr Biol 2005, 15:561-565.

46. Hu Y, Ghosh S, Amleh A, Yue W, Lu Y, Katz A, Li R: Modulation of aromatase expression by BRCA1: a possible link to tissue-specific tumor suppression. Oncogene 2005, 24:8343-8348.

47. Hong H, Yen HY, Brockmeyer A, Liu Y, Chodankar R, Pike MC, Stanczyk FZ, Maxson $R$, Dubeau $L$ : Changes in the mouse estrus cycle in response to BRCA1 inactivation suggest a potential link between risk factors for familial and sporadic ovarian cancer. Cancer Res 2010, 70:221-228.

48. Tanaka Y, Park JH, Tanwar PS, Kaneko-Tarui T, Mittal S, Lee HJ, Teixeira JM: Deletion of tuberous sclerosis 1 in somatic cells of the murine reproductive tract causes female infertility. Endocrinology 2012, 153:404-416.

49. Tanwar PS, Lee HJ, Zhang L, Zukerberg LR, Taketo MM, Rueda BR, Teixeira $J M$ : Constitutive activation of Beta-catenin in uterine stroma and smooth muscle leads to the development of mesenchymal tumors in mice. Biol Reprod 2009, 81:545-552.

50. Jamin SP, Arango NA, Mishina Y, Hanks MC, Behringer RR: Requirement of Bmpr1a for Mullerian duct regression during male sexual development. Nat Genet 2002, 32:408-410.

51. Fan HY, Liu Z, Paquet M, Wang J, Lydon JP, DeMayo FJ, Richards JS: Cell type-specific targeted mutations of Kras and Pten document proliferation arrest in granulosa cells versus oncogenic insult to ovarian surface epithelial cells. Cancer Res 2009, 69:6463-6472.

52. Fan HY, Liu Z, Cahill N, Richards JS: Targeted disruption of Pten in ovarian granulosa cells enhances ovulation and extends the life span of luteal cells. Mol Endocrinol 2008, 22:2128-2140.

53. Lague MN, Paquet M, Fan HY, Kaartinen MJ, Chu S, Jamin SP, Behringer RR, Fuller PJ, Mitchell A, Dore M, et al: Synergistic effects of Pten loss and 
WNT/CTNNB1 signaling pathway activation in ovarian granulosa cell tumor development and progression. Carcinogenesis 2008, 29:2062-2072.

54. Mullany LK, Liu Z, King ER, Wong KK, Richards JS: Wild-type tumor repressor protein 53 (Trp53) promotes ovarian cancer cell survival. Endocrinology 2012, 153:1638-1648.

55. Daikoku T, Jackson L, Besnard V, Whitsett J, Ellenson LH, Dey SK: Cellspecific conditional deletion of Pten in the uterus results in differential phenotypes. Gynecol Oncol 2011, 122:424-429.

56. Tanwar PS, Zhang L, Kaneko-Tarui T, Curley MD, Taketo MM, Rani P, Roberts DJ, Teixeira JM: Mammalian target of rapamycin is a therapeutic target for murine ovarian endometrioid adenocarcinomas with dysregulated Wnt/beta-catenin and PTEN. PLoS One 2011, 6:e20715.

57. Richards JS, Fan HY, Liu Z, Tsoi M, Lague MN, Boyer A, Boerboom D: Either Kras activation or Pten loss similarly enhance the dominant-stable CTNNB1-induced genetic program to promote granulosa cell tumor development in the ovary and testis. Oncogene 2012, 31:1504-1520.

58. Kim J, Coffey DM, Creighton CJ, Yu Z, Hawkins SM, Matzuk MM: High-grade serous ovarian cancer arises from fallopian tube in a mouse model. Proc Natl Acad Sci U S A 2012, 109:3921-3926.

59. Gonzalez G, Behringer RR: Dicer is required for female reproductive tract development and fertility in the mouse. Mol Reprod Dev 2009, 76:678-688.

60. Lei L, Jin S, Gonzalez G, Behringer RR, Woodruff TK: The regulatory role of Dicer in folliculogenesis in mice. Mol Cell Endocrinol 2010, 315:63-73.

61. Tanwar PS, Kaneko-Tarui T, Zhang L, Tanaka Y, Crum CP, Teixeira JM: Stromal Liver Kinase B1 [STK11] Signaling Loss Induces Oviductal Adenomas and Endometrial Cancer by Activating Mammalian Target of Rapamycin Complex 1. PLoS Genet 2012, 8:e1002906.

62. Siegenthaler JA, Tremper-Wells BA, Miller MW: Foxg1 haploinsufficiency reduces the population of cortical intermediate progenitor cells: effect of increased p21 expression. Cereb Cortex 2008, 18:1865-1875.

63. MacLean HE, Chiu WS, Ma C, McManus JF, Davey RA, Cameron R, Notini AJ Zajac JD: A floxed allele of the androgen receptor gene causes hyperandrogenization in male mice. Physiol Genomics 2008, 33:133-137.

64. Petit FG, Jamin SP, Kurihara I, Behringer RR, DeMayo FJ, Tsai MJ, Tsai SY: Deletion of the orphan nuclear receptor COUP-TFII in uterus leads to placental deficiency. Proc Natl Acad Sci U S A 2007, 104:6293-6298.

65. Lee JY, Ristow M, Lin X, White MF, Magnuson MA, Hennighausen L: RIP-Cre revisited, evidence for impairments of pancreatic beta-cell function. $J$ Biol Chem 2006, 281:2649-2653.

66. Flesken-Nikitin A, Choi KC, Eng JP, Shmidt EN, Nikitin AY: Induction of carcinogenesis by concurrent inactivation of p53 and Rb1 in the mouse ovarian surface epithelium. Cancer Res 2003, 63:3459-3463.

67. Clark-Knowles KV, Senterman MK, Collins O, Vanderhyden BC: Conditional inactivation of Brca1, p53 and $\mathrm{Rb}$ in mouse ovaries results in the development of leiomyosarcomas. PLoS One 2009, 4:e8534.

68. Quinn BA, Brake T, Hua X, Baxter-Jones K, Litwin S, Ellenson LH, Connolly DC: Induction of ovarian leiomyosarcomas in mice by conditional inactivation of Brca1 and p53. PLoS One 2009, 4:e8404.

69. Xing D, Scangas G, Nitta M, He L, Xu X, loffe YJ, Aspuria PJ, Hedvat CY, Anderson ML, Oliva $E$, et al: A role for BRCA1 in uterine leiomyosarcoma. Cancer Res 2009, 69:8231-8235.

70. Szabova L, Yin C, Bupp S, Guerin TM, Schlomer JJ, Householder DB, Baran ML, Yi M, Song Y, Sun W, et al: Perturbation of Rb, p53 and Brca1 or Brca2 cooperate in inducing metastatic serous epithelial ovarian cancer. Cancer Res 2012, 72:4141-4153.

71. Dannenberg JH, Schuijff $L$, Dekker $M$, van der Valk $M$, te Riele H: Tissuespecific tumor suppressor activity of retinoblastoma gene homologs p107 and p130. Genes Dev 2004, 18:2952-2962.

72. Saenz Robles MT, Symonds H, Chen J, Van Dyke T: Induction versus progression of brain tumor development: differential functions for the pRB- and p53-targeting domains of simian virus $40 \mathrm{~T}$ antigen. Mol Cell Biol 1994, 14:2686-2698.

73. Stubdal H, Zalvide J, Campbell KS, Schweitzer C, Roberts TM, DeCaprio JA: Inactivation of pRB-related proteins p130 and p107 mediated by the J domain of simian virus 40 large T antigen. Mol Cell Biol 1997, 17:4979-4990.

74. Laviolette LA, Garson K, Macdonald EA, Senterman MK, Courville K, Crane CA, Vanderhyden BC: 17beta-estradiol accelerates tumor onset and decreases survival in a transgenic mouse model of ovarian cancer. Endocrinology 2010, 151:929-938.
75. Ahuja D, Saenz-Robles MT, Pipas JM: SV40 large T antigen targets multiple cellular pathways to elicit cellular transformation. Oncogene 2005, 24:7729-7745.

76. Dinulescu DM, Ince TA, Quade BJ, Shafer SA, Crowley D, Jacks T: Role of Kras and Pten in the development of mouse models of endometriosis and endometrioid ovarian cancer. Nat Med 2005, 11:63-70.

77. Kinross KM, Brown DV, Kleinschmidt M, Jackson S, Christensen J, Cullinane C, Hicks RJ, Johnstone RW, McArthur GA: In vivo activity of combined PI3K/ mTOR and MEK inhibition in a Kras(G12D);Pten deletion mouse model of ovarian cancer. Mol Cancer Ther 2011, 10:1440-1449.

78. Scarlett UK, Rutkowski MR, Rauwerdink AM, Fields J, Escovar-Fadul X, Baird J, Cubillos-Ruiz JR, Jacobs AC, Gonzalez JL, Weaver J, et al: Ovarian cancer progression is controlled by phenotypic changes in dendritic cells. J Exp Med 2012, 209:495-506.

79. Kinross KM, Montgomery KG, Kleinschmidt M, Waring P, Ivetac I, Tikoo A, Saad M, Hare L, Roh V, Mantamadiotis T, et al: An activating Pik3ca mutation coupled with Pten loss is sufficient to initiate ovarian tumorigenesis in mice. J Clin Invest 2012, 122:553-557.

80. Wu R, Hendrix-Lucas N, Kuick R, Zhai Y, Schwartz DR, Akyol A, Hanash S, Misek DE, Katabuchi $H$, Williams BO, et al: Mouse model of human ovarian endometrioid adenocarcinoma based on somatic defects in the Wnt/ beta-catenin and PI3K/Pten signaling pathways. Cancer Cell 2007, 11:321-333

81. Wu R, Hu TC, Rehemtulla A, Fearon ER, Cho KR: Preclinical testing of PI3K/ AKT/mTOR signaling inhibitors in a mouse model of ovarian endometrioid adenocarcinoma. Clin Cancer Res 2011, 17:7359-7372.

82. Zhu Y, Maric J, Nilsson M, Brannstrom M, Janson PO, Sundfeldt K: Formation and barrier function of tight junctions in human ovarian surface epithelium. Biol Reprod 2004, 71:53-59.

83. Bergelson JM, Cunningham JA, Droguett G, Kurt-Jones EA, Krithivas A, Hong JS, Horwitz MS, Crowell RL, Finberg RW: Isolation of a common receptor for Coxsackie B viruses and adenoviruses 2 and 5. Science 1997, 275:1320-1323.

84. Wickham TJ, Mathias P, Cheresh DA, Nemerow GR: Integrins alpha v beta 3 and alpha v beta 5 promote adenovirus internalization but not virus attachment. Cell 1993, 73:309-319.

85. Cohen CJ, Shieh JT, Pickles RJ, Okegawa T, Hsieh JT, Bergelson JM: The coxsackievirus and adenovirus receptor is a transmembrane component of the tight junction. Proc Natl Acad Sci U S A 2001, 98:15191-15196.

86. Pearson AS, Koch PE, Atkinson N, Xiong M, Finberg RW, Roth JA, Fang B: Factors limiting adenovirus-mediated gene transfer into human lung and pancreatic cancer cell lines. Clin Cancer Res 1999, 5:4208-4213.

87. Excoffon KJ, Gansemer ND, Mobily ME, Karp PH, Parekh KR, Zabner J: Isoform-specific regulation and localization of the coxsackie and adenovirus receptor in human airway epithelia. PLoS One 2010, 5:e9909.

88. Lutschg V, Boucke K, Hemmi S, Greber UF: Chemotactic antiviral cytokines promote infectious apical entry of human adenovirus into polarized epithelial cells. Nat Commun 2011, 2:391.

89. Johansson C, Jonsson M, Marttila M, Persson D, Fan XL, Skog J, Frangsmyr L, Wadell G, Arnberg N: Adenoviruses use lactoferrin as a bridge for CARindependent binding to and infection of epithelial cells. J Virol 2007, 81:954-963

90. Arici A, Oral E, Bukulmez O, Buradagunta S, Engin O, Olive DL: Interleukin-8 expression and modulation in human preovulatory follicles and ovarian cells. Endocrinology 1996, 137:3762-3769.

91. Palter SF, Mulayim N, Senturk L, Arici A: Interleukin-8 in the human fallopian tube. J Clin Endocrinol Metab 2001, 86:2660-2667.

92. Teng $C T$, Beard C, Gladwell W: Differential expression and estrogen response of lactoferrin gene in the female reproductive tract of mouse, rat, and hamster. Biol Reprod 2002, 67:1439-1449.

93. Yanaihara A, Mitsukawa K, Iwasaki S, Otsuki K, Kawamura T, Okai T: High concentrations of lactoferrin in the follicular fluid correlate with embryo quality during in vitro fertilization cycles. Fertil Steril 2007, 87:279-282.

94. Saito F, Tashiro H, To Y, Ohtake H, Ohba T, Suzuki A, Katabuchi H: Mutual contribution of Pten and estrogen to endometrial carcinogenesis in a PtenloxP/loxP mouse model. Int J Gynecol Cancer 2011, 21:1343-1349.

95. Hunter KW: Mouse models of cancer: does the strain matter? Nat Rev Cancer 2012, 12:144-149.

96. Churchill GA, Airey DC, Allayee H, Angel JM, Attie AD, Beatty J, Beavis WD, Belknap JK, Bennett B, Berrettini W, et al: The Collaborative Cross, a 
community resource for the genetic analysis of complex traits. Nat Genet 2004, 36:1133-1137.

97. Weaver Z, Montagna C, Xu X, Howard T, Gadina M, Brodie SG, Deng CX,

Ried T: Mammary tumors in mice conditionally mutant for Brca1 exhibit gross genomic instability and centrosome amplification yet display a recurring distribution of genomic imbalances that is similar to human breast cancer. Oncogene 2002, 21:5097-5107.

98. Laviolette LA, Ethier JF, Senterman MK, Devine PJ, Vanderhyden BC: Induction of a menopausal state alters the growth and histology of ovarian tumors in a mouse model of ovarian cancer. Menopause 2011, 18:549-557.

doi:10.1186/1757-2215-5-39

Cite this article as: Garson et al: Technical challenges and limitations of current mouse models of ovarian cancer. Journal of Ovarian Research 2012 5:39.

\section{Submit your next manuscript to BioMed Central and take full advantage of:}

- Convenient online submission

- Thorough peer review

- No space constraints or color figure charges

- Immediate publication on acceptance

- Inclusion in PubMed, CAS, Scopus and Google Scholar

- Research which is freely available for redistribution 